\title{
Nocebo effect in multiple system atrophy: systematic review and meta-analysis of placebo-controlled clinical trials
}

\author{
Zi-Xuan Wang $^{1,2} \cdot$ Nan-Nan Zhang ${ }^{1} \cdot$ Hai-Xia Zhao ${ }^{3} \cdot$ Jie Song $^{1}$
}

Received: 3 March 2021 / Accepted: 15 November 2021 / Published online: 1 January 2022

(c) The Author(s) 2021

\begin{abstract}
Background Nocebo effect is prevalent among neurological diseases, resulting in low adherence and treatment outcome. We sought to examine the nocebo effect in randomized controlled trials (RCTs) in multiple system atrophy (MSA).

Methods We searched RCTs in MSA from Medline since September, 2021. RCTs for drug treatment conducted in adult MSA patients with more than 5 cases in each treatment arm were included. We assessed the number of dropout due to placebo intolerance. We also did a symptomatic/disease-modifying subgroup analysis based on two different treatment purposes. The STATA software was used for statistical analysis. Overall heterogeneity was assessed using the Cochran $Q$ and $I^{2}$.

Results Data were extracted from 11 RCTs fulfilling our search criteria. Of 540 placebo-treated patients, $64.2 \%$ reported at least one adverse event (AE) and 7.5\% reported dropout because of AEs. The chance of dropping out because of an AE and experiencing at least one $\mathrm{AE}$ did not differ between placebo and active drug treatment arms. Besides, the pooled nocebo dropout rate in the symptomatic subgroup was similar to that of the disease-modifying subgroup.

Conclusion In MSA RCTs, nocebo dropout rate was not at a low level among neurological disorders. Nocebo effect was an important reason of dropout because of AE in placebo and active drug treatment arms. Different treatment purposes may not influence nocebo effect.
\end{abstract}

Keywords Nocebo effect $\cdot$ Placebo $\cdot$ Multiple system atrophy $\cdot$ Randomized controlled trials $\cdot$ Meta-analysis

\section{Introduction}

The psychosocial context can play an essential role in most medical treatments. Positive physiological or psychological effects induced by the treatment context are referred to as well- known placebo effects. Placebo effect has impact on therapeutic response, adherence, and quality of life [1,2]. On the other hand, the negative effects the treatment context induces are defined as nocebo effects. Nocebo effect refers to the experience of AEs from administration of an inert substance such as placebo. This phenomenon is influenced by patients' anticipations,

Zi-Xuan Wang

zixuanwang2013@163.com

1 Department of Geriatrics, the Affiliated Hospital of Qingdao University, Qingdao 266071, China

2 Institute of Neuroregeneration and Neurorehabilition, Qingdao University, Qingdao 266071, China

3 Department of Neurology, the Third People's Hospital of Qingdao, Qingdao University, Qingdao 266000, China previous experiences to medication, awareness of drug side-effect profiles, psychological factors including stress and anxiety, and the interactions between clinicians and patients [3]. Nocebo effects interfere negatively with medical and treatment outcomes and physicians should be able to propose strategies for preventing or even overcoming their influence so as to optimize treatment outcomes [4].

Nocebo effect is prevalent among neurological diseases and a variability in the magnitude of nocebo effect has been demonstrated in various neurological disorders [5]. To date, there is sparse reporting of nocebo in MSA drug treatment, with only a RCT of MSA [6] having been investigated. The aim of our study is to estimate the frequency and strength of nocebo effects in RCTs of MSA. We also sought to examine whether different treatment purposes influenced nocebo effect. In consistent with the former studies, the dropout rate due to placebo-related AE was also used as measure of nocebo effect in our study. 


\section{Methods}

This systematic review and meta-analysis was conducted according to the Preferred Reporting Items for Systematic Reviews and Meta-Analyses (PRISMA) guidelines [7].

\section{Data source search strategy}

A computer-based PubMed literature search was conducted on 28th Sep, 2021. We used two Medical Subject Headings (MeSH) terms. Term A was "placebo" and Term B was "multiple system atrophy" or "MSA." Limitations were set to specify language to be English.

\section{Study selection}

We included the studies if they met the following criteria: (1) referred specifically to MSA; (2) referred specifically to humans; (3) RCTs; (4) pharmaceutical studies; (5) there was a placebo arm; (6) each treatment arm had at least 5 patients; (7) adult participants; and (8) detailed data of drop-outs in each treatment arm were available in the report; (9) excluding reviews, letters without original data, editorials; (10) when there was more than one publication from the same studied population, only data from the most comprehensive report was included in our analysis and the remaining were excluded.

\section{Data extraction and quality assessment}

Two reviewers independently performed the search, reviewing all articles and collecting data. Items were extracted from each study and the extracted information included: information on the article identification; year of publication; evaluation period; total number of subjects; number of placebo-treated subjects; total number of placebo deaths; number of placebo-treated subjects who dropped out because of AEs; number of placebo-treated subjects who dropped out for other reasons; number of male subjects treated with placebo; mean age of placebotreated subjects; number of active drug-treated subjects; total number of active drug deaths; number of active drug-treated subjects who dropped out because of AEs; number of active drug-treated subjects who dropped out for other reasons; number of male subjects treated with active drug; mean age of active drug-treated subjects; active drug; disease-modifying drug or symptomatic drug; route of drug administration and geographic location. The authors independently evaluated each of the included studies according to modified JADAD scale [8]. RCT with a JADAD score $\geq 4$ was considered a high-quality study.

\section{Statistical analysis}

The meta-analysis was conducted using STATA 15.0 (Copyright 1985-2017 Stata Corp LP). We calculated the pooled dropout rates because of any AEs for each group and its 95\% confidence intervals, as well as the pooled AE rates for each group and its $95 \%$ confidence intervals. We choose odds ratios (ORs) and 95\% confidence intervals (CIs) as the appropriate parameters to evaluate the dichotomous outcomes, such as the dropout rate. Overall heterogeneity was assessed using the Cochran $Q$ test ( $p$ value $>0.05$ indicates lack of heterogeneity among studies) and $I^{2}$ value (values $<50 \%$ as low heterogeneity). The fixed-effect model was applied if there was no or low heterogeneity. Data were analyzed using a random effects model if there was high heterogeneity. Pooled ORs for comparison between the two arms were estimated as illustrated in the forest plots. The Egger's test was used to assess the presence of asymmetry in the funnel plots ( $p$ value $>0.05$ indicates no publication bias).

\section{Results}

The process of the article selection is presented in Fig. 1. After the application of our search strategy, we found that eleven RCTs [9-19] published between 1996 and 2021, that met our selection criteria. The included RCTs have a JADAD score of 4 or greater. Five hundred forty placebotreated MSA patients and 558 active drug-treated MSA patients were included. Data details of the included studies are presented in the Table 1.

\section{Dropouts in placebo and active drug arm}

The pooled estimate of dropout rate because of AEs other than death in placebo-treated patients and active drugtreated patients was 7.5\% (95\% CI=3.0-13.7\%) and $11.8 \%$ (95\% CI $=5.1-20.8 \%)$ respectively. One study [12] reported no dropouts because of AEs in both study arms and other ten studies were included in the final meta-analysis. As illustrated in the forest plot (Fig. 2a), the chance of dropping out because of AEs other than death did not differ between placebo and active-drug treatment arms $(O R=0.626,95 \%$ $C I=0.389-1.007, p=0.053)$. There was no heterogeneity among the included studies $\left(p=0.925, I^{2}=0 \%\right)$. As shown in the funnel plots (Fig. 2b), there was no publication bias among the included studies (Egger test: $z=-0.45$, $p=0.655)$. Besides, 17 deaths occurred in placebo-treated 
Fig. 1 The PRISMA chart showing study screening process

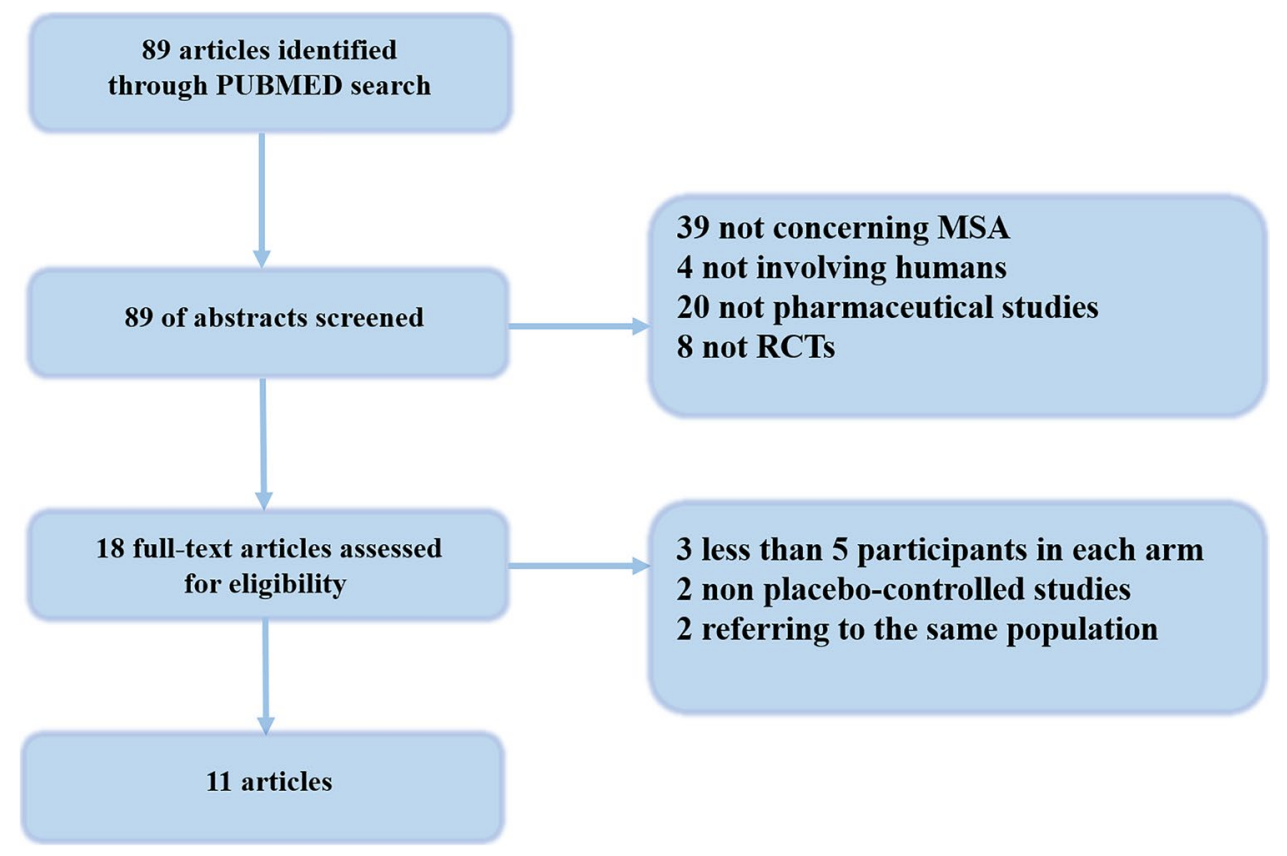

patients of 7 studies and 22 deaths occurred in active drugtreated patients of 8 studies (Table 1). All of the deaths were considered unrelated to active treatment, except for those not specified in the articles.

\section{Adverse events in placebo and active drug arm}

Only eight of the studies [10, 11, 14-19] reported in detail the exact number of patients experiencing at least one $\mathrm{AE}$ in the study groups. The pooled estimate of the percentage of placebo treated patients with at least one AE was $64.2 \%(95 \% C I=43.2-82.6 \%)$, compared to $72.4 \%(95 \%$ $C I=53.4-88.0 \%$ ) for active drug treated patients. As illustrated in the forest plot (Fig. 3a), the chance of experiencing at least one $\mathrm{AE}$ did not differ between placebo and active drug treatment arms $(O R=0.732,95 \% C I=0.490-1.092$, $p=0.126)$. There was no heterogeneity among the studies included in the meta-analysis $\left(p=0.977, I^{2}=0.0 \%\right)$. As shown in the funnel plots (Fig. 3b), there was no publication bias among the included studies (Egger test: $z=-0.74$, $p=0.458)$.

\section{Dropouts for MSA patients with two different purposes of experimental treatment}

The MSA patients included in 11 studies were classified into two subgroups according to different purposes of experimental treatment. Three of the studies were symptomatic and eight of the studies were disease-modifying (Table 1). In the two subgroups, the chance of dropping out because of AEs other than death did not differ between placebo and activedrug treatment arms (symptomatic subgroup: $O R=0.484$, 95\% $C I=0.173-1.358, p=0.168$; disease-modifying subgroup: $O R=0.672,95 \% C I=0.392-1.149, p=0.146)$. There was also no heterogeneity among the studies included in two subgroups (symptomatic subgroup: $p=0.895, I^{2}=0.0 \%$; disease-modifying subgroup: $p=0.775, I^{2}=0.0 \%$ ). Moreover, the pooled nocebo dropout rate in the symptomatic subgroup $(9.2 \%, 95 \% C I=3.7-16.7 \%)$ was similar to that of the disease-modifying subgroup $(7.5 \%, 95 \% C I=2.3-15.4 \%)$.

\section{Discussion}

This meta-analysis of 11 RCTs showed the chance of dropping out because of $\mathrm{AE}$ other than death and experiencing at least one AE did not differ between placebo and active drug treatment arms. The dropout rates were similar across the study arms and independent of the study arm to which they belonged. This indicates that nocebo effect is an important reason of dropout because of AEs other than death in placebo and active drug treatment arms in MSA RCTs.

Nocebo varies significantly among neurological diseases. Weighed against other neurological disorders investigated with identical methodology, comparable to those found in fibromyalgia (nocebo dropout rate 9.5\%, 95\% CI $=8.3-10.9 \%$; nocebo AE rate $67.2 \%, 95 \%$ $C I=51.0-81.5 \%)$ and chronic inflammatory demyelinating polyneuropathy (CIDP) (nocebo dropout rate $2.1 \%$, 95\% $C I=0.3-7.3 \%$; nocebo $\mathrm{AE}$ rate $42 \%$ ) [20], the nocebo dropout rate and nocebo $\mathrm{AE}$ rate were not at a low level in MSA among neurological disorders and close to 


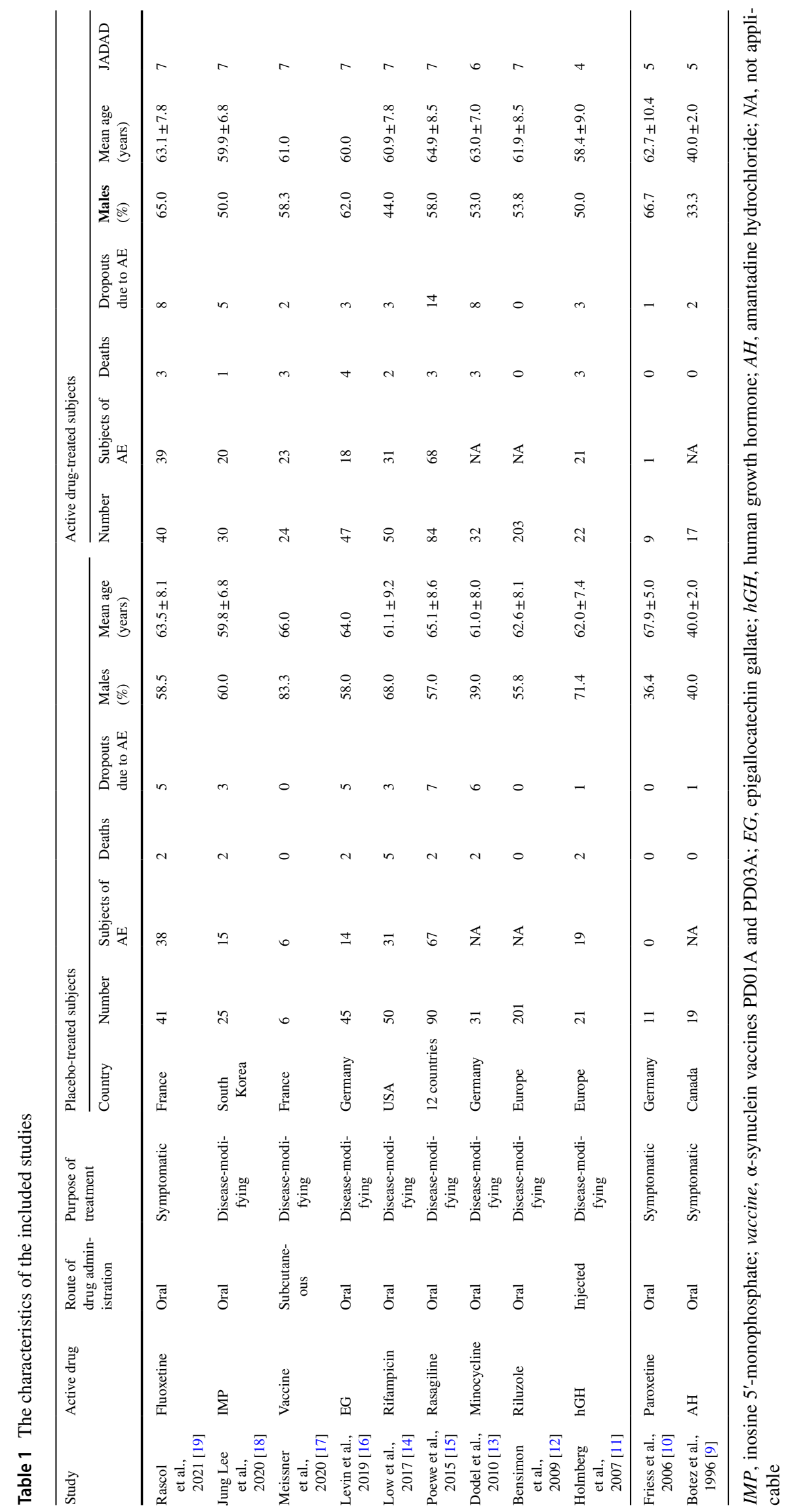


those found in Alzheimer's disease (AD) (nocebo dropout rate $6.6 \%, 95 \% C I=5.3-8.4 \%$, nocebo $\mathrm{AE}$ rate $57.8 \%$, 95\% $C I=50.1-66.7 \%$ ) [21] and Parkinson's disease (PD) (nocebo dropout rate $8.8 \%, 95 \% C I=6.8-11.5 \%$, nocebo $\mathrm{AE}$ rate $64.7 \%, 95 \% \mathrm{CI}=53.6-74.4 \%$ ) [22]. In terms of neurobiological mechanisms, high nocebo responses were associated with activation of cholecystokinin (CCK) system, hyperactivity of the hypothalamic-pituitary-adrenal (HPA) axis, deactivation of dopamine (DA), and opioid release. Nocebo system involves different brain regions and can modulate the outcome of a given therapy in a negative way [23]. MSA is a neurodegenerative disorder characterized by prominent autonomic failure associated with parkinsonism, cerebellar ataxia, or both [24]. Patients with MSA showed defective DA and opioids systems $[25,26]$. MSA patients are affected in some regions of the brain where nocebo effects come into play [27, 28]. Thus, as we found, powerful nocebo should be expected in MSA. Furthermore, similarities in nocebo rates among the neurodegenerative diseases enhance the theory that nocebo rates may vary depending on the pathophysiology and the pathology of the disease [23].

A treatment may be investigated with a potential disease-modifying purpose, others as a symptomatic drug. From the conceptual perspective of the nocebo effect, different treatment purposes may influence patients' expectation towards the experimental drug and the study participation. We did a further subgroup analysis. Our results showed that in the symptomatic subgroup/diseasemodifying subgroup, the chance of dropping out because of AEs other than death did not differ between placebo and active-drug treatment arms. Moreover, the pooled nocebo dropout rate in the symptomatic subgroup was similar to that of the disease-modifying subgroup. Our results indicated that nocebo effect did not appear to be affected by different purposes of experimental treatment in MSA RCTs.

\section{Study limitations}

Our results should be interpreted with caution due to the limitations of the design. Firstly, the trail dropouts did not accurately reflect the nocebo effects and its severity. Because it is difficult to accurately attribute AEs in the placebo group to drug administration or a consequence of disease worsening or non-specific symptoms, dropouts used as measure of nocebo effect exist deficiency. Secondly, this meta-analysis was performed using only eleven RCTs, which involved pharmacotherapy in MSA and met our stringent inclusion criteria. Some MSA-related RCTs, which involved other diseases such as neurogenic orthostatic hypotension and pure autonomic failure, were not included in our analysis.

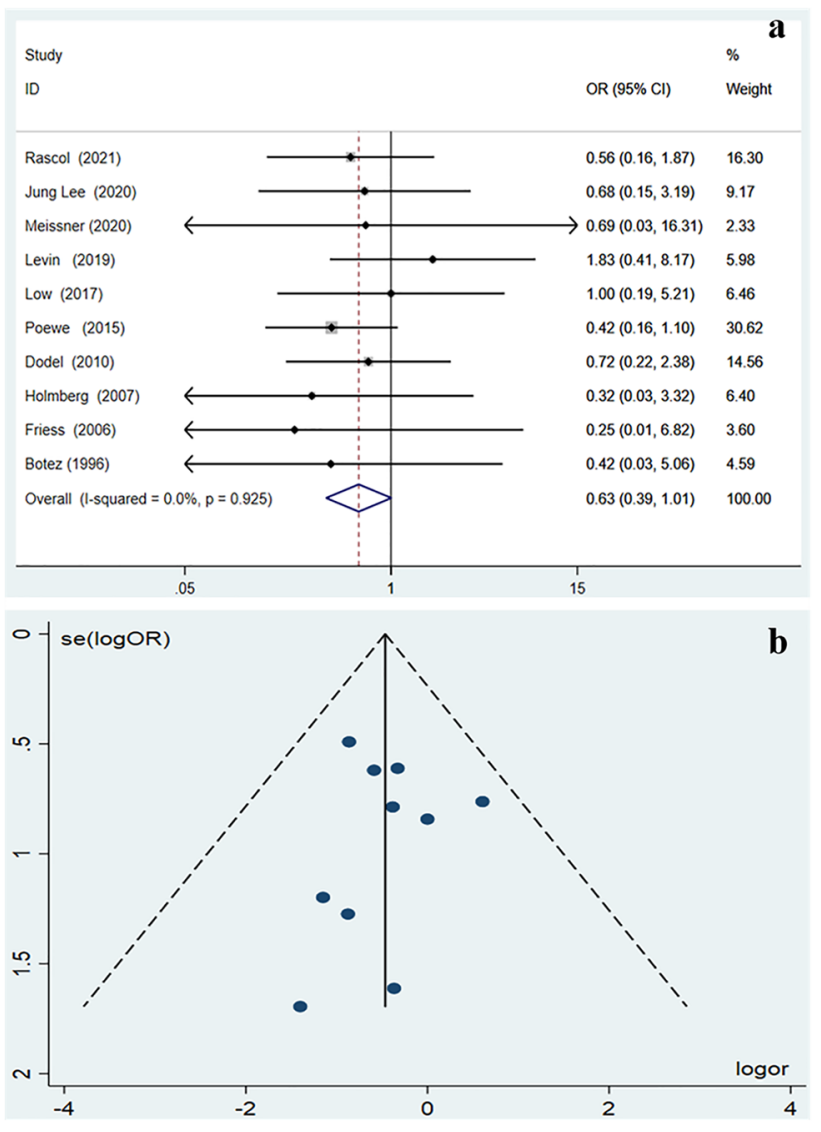

Fig. 2 a Meta-analysis results as illustrated in the forest plot regarding the percentage of patients who dropped out because of an adverse event. b Meta-analysis results as illustrated in the funnel plot regarding the percentage of patients who dropped out because of an adverse event

Therefore, our estimates may not fully reflect the extent of nocebo effect in MSA patients.

\section{Implications for clinical trials and clinical practice}

Clinicians should be aware of the nocebo phenomenon and attempt to reduce nocebo effect in clinical trials and clinical practice [4]. A number of accepted strategies minimizing nocebo effect, including creating a good physician-patient relationship, increasing empathic attitudes, exposing information suitably, decreasing expectations of AEs, still applicable to MSA clinical trials and clinical practice. It is also useful for clinicians to acknowledge that reported nocebo $\mathrm{AE}$ rates and nocebo dropout rate are not low in RCTs for MSA. A similar dropout rate in both placebo and active-drug arms implicates that most of the dropout in RCTs of MSA are due to nocebo effect. The causal relationship between AEs and 


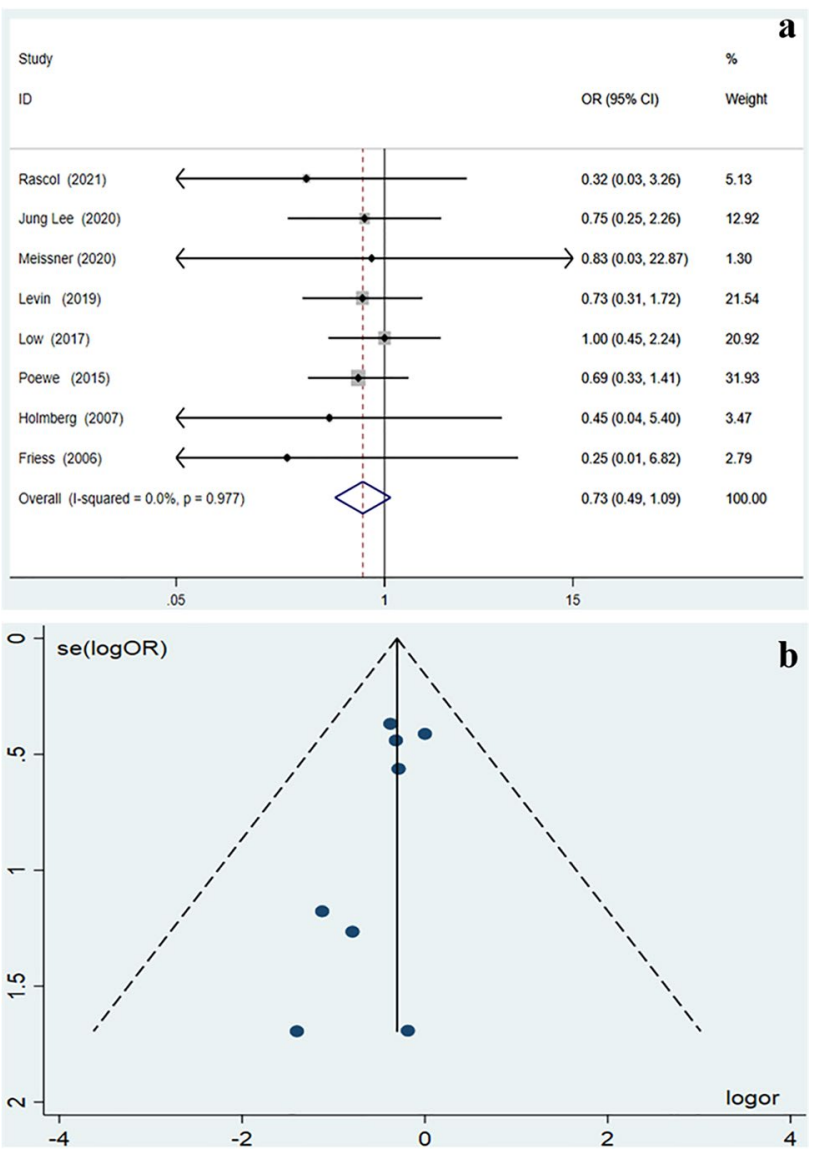

Fig. 3 a Meta-analysis results as illustrated in the forest plot regarding the percentage of patients who experienced at least one adverse event. b Meta-analysis results as illustrated in the funnel plot regarding the percentage of patients who experienced at least one adverse event

drugs should be analyzed prudently and be achievable with a combination of detailed safety reports and structured $\mathrm{AE}$ assessments. Clinicians should rely more on objective investigations than on subjective symptoms reported by patients. Furthermore, because different purposes of treatment did not appear to be relevant to nocebo effect, clinicians did not worry about the impact of treatment purpose on nocebo effect in MSA RCTs.

\section{Conclusion}

In RCTs for MSA, $64.2 \%$ of the participants reported AEs related to nocebo and $7.5 \%$ of the participants reported dropout related to nocebo. With dropout rate as measure of nocebo effect, the total patients participating in those RCTs reported similar dropout independently of the study arm they belonged, which suggests some AEs arise from the anticipated pharmacological effects of the drug other than active drug itself. Nocebo effect was the important reason of dropout because of $\mathrm{AE}$ in the placebo and the active drug groups and is an important factor for treatment adherence in MSA patients during clinical trials and in clinical practice. Furthermore, the nocebo effect does not appear to be affected by different purposes of experimental treatment in MSA RCTs.

Author contribution (I) Conception and design: Z Wang; (II) administrative support: none; (III) provision of study materials or patients: none; (IV) collection and assembly of data: Z Wang, H Zhao; (V) data analysis and interpretation: Z Wang, N Zhang; (VI) manuscript writing: all authors; (VII) final approval of manuscript: all authors.

Funding This work was supported by grants from the Qingdao Postdoctoral Application Research Project, Qilu hygiene and health leading talents cultivation project, and the Clinical Medicine + X Project Fund, Medical School of Qingdao University.

\section{Declarations}

Ethics approval This is a meta-analysis; the study did not use any private patient data.

Conflict of interest The authors declare no competing interests.

Open Access This article is licensed under a Creative Commons Attribution 4.0 International License, which permits use, sharing, adaptation, distribution and reproduction in any medium or format, as long as you give appropriate credit to the original author(s) and the source, provide a link to the Creative Commons licence, and indicate if changes were made. The images or other third party material in this article are included in the article's Creative Commons licence, unless indicated otherwise in a credit line to the material. If material is not included in the article's Creative Commons licence and your intended use is not permitted by statutory regulation or exceeds the permitted use, you will need to obtain permission directly from the copyright holder. To view a copy of this licence, visit http://creativecommons.org/licenses/by/4.0/.

\section{References}

1. Hashmi JA (2018) Placebo effect: theory, mechanisms and teleological roots. Int Rev Neurobiol 139:233-253. https://doi.org/10. 1016/bs.irn.2018.07.017

2. Girach A, Aamir A, Zis P (2019) The neurobiology under the placebo effect. Drugs Today (Barc) 55:469-476. https://doi.org/ 10.1358/dot.2019.55.7.3010575

3. Kleine-Borgmann J, Bingel U (2018) Nocebo effects: neurobiological mechanisms and strategies for prevention and optimizing treatment. Int Rev Neurobiol 138:271-283. https://doi.org/10. 1016/bs.irn.2018.02.005

4. Chavarria V, Vian J, Pereira C, Data-Franco J, Fernandes BS, Berk M, Dodd S (2017) The placebo and nocebo phenomena: their clinical management and impact on treatment outcomes. Clin Ther 39:477-486. https://doi.org/10.1016/j.clinthera.2017.01.031 
5. Varma A, Zis P (2019) Nocebo effect in myasthenia gravis: systematic review and meta-analysis of placebo-controlled clinical trials. Acta Neurol Belg 119:257-264. https://doi.org/10.1007/ s13760-019-01143-1

6. Ferreira JJ, Trenkwalder C, Mestre TA (2018) Placebo and nocebo responses in other movement disorders besides Parkinson's disease: how much do we know? Mov Disord 33:1228-1235. https:// doi.org/10.1002/mds.113

7. Moher D, Liberati A, Tetzlaff J, Altman DG and Group P (2009) Preferred reporting items for systematic reviews and meta-analyses: the PRISMA statement. BMJ 339:b2535. https://doi.org/10. 1136/bmj.b2535

8. Jadad AR, Moore RA, Carroll D, Jenkinson C, Reynolds DJ, Gavaghan DJ, McQuay HJ (1996) Assessing the quality of reports of randomized clinical trials: is blinding necessary? Control Clin Trials 17:1-12. https://doi.org/10.1016/0197-2456(95)00134-4

9. Botez MI, Botez-Marquard T, Elie R, Pedraza OL, Goyette K, Lalonde R (1996) Amantadine hydrochloride treatment in heredodegenerative ataxias: a double blind study. J Neurol Neurosurg Psychiatry 61:259-264. https://doi.org/10.1136/jnnp.61.3.259

10. Friess E, Kuempfel T, Modell S, Winkelmann J, Holsboer F, Ising M, Trenkwalder C (2006) Paroxetine treatment improves motor symptoms in patients with multiple system atrophy. Parkinsonism Relat Disord 12:432-437. https://doi.org/10.1016/j.parkreldis. 2006.04.002

11. Holmberg B, Johansson JO, Poewe W, Wenning G, Quinn NP, Mathias C, Tolosa E, Cardozo A, Dizdar N, Rascol O, Slaoui T, Growth-Hormone MSASG, European MSASG (2007) Safety and tolerability of growth hormone therapy in multiple system atrophy: a double-blind, placebo-controlled study. Mov Disord 22:1138-1144. https://doi.org/10.1002/mds.21501

12. Bensimon G, Ludolph A, Agid Y, Vidailhet M, Payan C, Leigh PN and Group NS (2009) Riluzole treatment, survival and diagnostic criteria in Parkinson plus disorders: the NNIPPS study. Brain 132:156-171. https://doi.org/10.1093/brain/awn291

13. Dodel R, Spottke A, Gerhard A, Reuss A, Reinecker S, Schimke N, Trenkwalder C, Sixel-Doring F, Herting B, Kamm C, Gasser T, Sawires M, Geser F, Kollensperger M, Seppi K, Kloss M, Krause M, Daniels C, Deuschl G, Bottger S, Naumann M, Lipp A, Gruber D, Kupsch A, Du Y, Turkheimer F, Brooks DJ, Klockgether T, Poewe W, Wenning G, Schade-Brittinger C, Oertel WH, Eggert K (2010) Minocycline 1-year therapy in multiple-systematrophy: effect on clinical symptoms and [(11)C] (R)-PK11195 PET (MEMSA-trial). Mov Disord 25:97-107. https://doi.org/10. 1002/mds.22732

14. Low PA, Robertson D, Gilman S, Kaufmann H, Singer W, Biaggioni I, Freeman R, Perlman S, Hauser RA, Cheshire W, Lessig S, Vernino S, Mandrekar J, Dupont WD, Chelimsky T, Galpern WR (2014) Efficacy and safety of rifampicin for multiple system atrophy: a randomised, double-blind, placebo-controlled trial. Lancet Neurol 13:268-275. https://doi.org/10.1016/S1474-4422(13) 70301-6

15. Poewe W, Seppi K, Fitzer-Attas CJ, Wenning GK, Gilman S, Low PA, Giladi N, Barone P, Sampaio C, Eyal E, Rascol O, Rasagiline-for MSAi, (2015) Efficacy of rasagiline in patients with the parkinsonian variant of multiple system atrophy: a randomised, placebo-controlled trial. Lancet Neurol 14:145-152. https://doi. org/10.1016/S1474-4422(14)70288-1

16. Levin J, Maass S, Schuberth M, Giese A, Oertel WH, Poewe W, Trenkwalder C, Wenning GK, Mansmann U, Sudmeyer M, Eggert K, Mollenhauer B, Lipp A, Lohle M, Classen J, Munchau A, Kassubek J, Gandor F, Berg D, Egert-Schwender S, Eberhardt C, Paul F, Botzel K, Ertl-Wagner B, Huppertz HJ, Ricard I, Hoglinger GU and Group PS (2019) Safety and efficacy of epigallocatechin gallate in multiple system atrophy (PROMESA): a randomised, double-blind, placebo-controlled trial. Lancet Neurol 18:724-735. https://doi.org/10.1016/S1474-4422(19)30141-3

17. Meissner WG, Traon AP, Foubert-Samier A, Galabova G, Galitzky M, Kutzelnigg A, Laurens B, Luhrs P, Medori R, Peran P, Sabatini U, Vergnet S, Volc D, Poewe W, Schneeberger A, Staffler G, Rascol O, Investigators AFFS (2020) A phase 1 randomized trial of specific active alpha-Synuclein immunotherapies PD01A and PD03A in multiple system atrophy. Mov Disord 35:19571965. https://doi.org/10.1002/mds.28218

18. Jung Lee J, Han Yoon J, Jin Kim S, Soo Yoo H, Jong Chung S, Hyun Lee Y, Yun Kang S, Shin HW, Keun Song S, Yong Hong J, Sunwoo M, Eun Lee J, Sam Baik J, Sohn YH, Hyu Lee P (2020) Inosine 5'-monophosphate to raise serum uric acid level in multiple system atrophy (IMPROVE-MSA study). Clin Pharmacol Ther. https://doi.org/10.1002/cpt.2082

19. Rascol O, Cochen de Cock V, Pavy-Le Traon A, Foubert-Samier A, Thalamas C, Sommet A, Rousseau V, Perez-Lloret S, Fabbri M, Azulay JP, Corvol JC, Couratier P, Damier P, Defebvre L, Durif F, Geny C, Houeto JL, Remy P, Tranchant C, Verin M, Tison F, Meissner WG and Group M-FS (2021) Fluoxetine for the symptomatic treatment of multiple system atrophy: the MSAFLUO trial. Mov Disord 36:1704-1711. https://doi.org/10.1002/ mds. 28569

20. Zis P, Hadjivassiliou M, Sarrigiannis PG, Jenkins TM, Mitsikostas DD (2018) Nocebo in chronic inflammatory demyelinating polyneuropathy; a systematic review and meta-analysis of placebocontrolled clinical trials. J Neurol Sci 388:79-83. https://doi.org/ 10.1016/j.jns.2018.03.009

21. Zis P, Mitsikostas DD (2015) Nocebo in Alzheimer's disease; meta-analysis of placebo-controlled clinical trials. J Neurol Sci 355:94-100. https://doi.org/10.1016/j.jns.2015.05.029

22. Stathis P, Smpiliris M, Konitsiotis S, Mitsikostas DD (2013) Nocebo as a potential confounding factor in clinical trials for Parkinson's disease treatment: a meta-analysis. Eur J Neurol 20:527-533. https://doi.org/10.1111/ene.12014

23. Planes S, Villier C, Mallaret M (2016) The nocebo effect of drugs. Pharmacol Res Perspect 4:e00208. https://doi.org/10.1002/prp2. 208

24. Fanciulli A, Stankovic I, Krismer F, Seppi K, Levin J, Wenning GK (2019) Multiple system atrophy. Int Rev Neurobiol 149:137192. https://doi.org/10.1016/bs.irn.2019.10.004

25. Kim HW, Kim JS, Oh M, Oh JS, Lee SJ, Oh SJ, Chung SJ, Lee CS (2016) Different loss of dopamine transporter according to subtype of multiple system atrophy. Eur J Nucl Med Mol Imaging 43:517-525. https://doi.org/10.1007/s00259-015-3191-6

26. Rinne JO, Burn DJ, Mathias CJ, Quinn NP, Marsden CD, Brooks DJ (1995) Positron emission tomography studies on the dopaminergic system and striatal opioid binding in the olivopontocerebellar atrophy variant of multiple system atrophy. Ann Neurol 37:568-573. https://doi.org/10.1002/ana.410370505

27. Benarroch EE, Schmeichel AM, Low PA, Parisi JE (2010) Differential involvement of the periaqueductal gray in multiple system atrophy. Auton Neurosci 158:111-117. https://doi.org/10.1016/j. autneu.2010.07.009

28. Cersosimo MG, Benarroch EE (2013) Central control of autonomic function and involvement in neurodegenerative disorders. Handb Clin Neurol 117:45-57. https://doi.org/10.1016/B978-0444-53491-0.00005-5

Publisher's note Springer Nature remains neutral with regard to jurisdictional claims in published maps and institutional affiliations. 